Abstract-Migrations of anadromous sea lamprey (Petromyzon marinus) from marine ecosystems serve as vectors of nutrients into freshwater food webs. Larval sea lamprey reside in streams for 6-8 years as deposit feeders before metamorphosing into juveniles and migrating to the ocean. Previous work has shown that carcass nutrients, which result from the death of adult lamprey after spawning, increase stream productivity and are consumed by larvae. This may increase larval growth rates and enhance earlier metamorphosis. We examined the sensitivity of life-history parameters and influence of nutrients from carcasses of sea lamprey on the age and growth of larval conspecifics with a deterministic stock-recruitment model. We hypothesized that variability in growth among larval populations is productivity mediated and we compared modeled populations in which larvae receive added growth benefits from carcass nutrients with populations that do not. The results of our simulation indicate that increases in larval growth and lower age at metamorphosis over time lead to an increase in spawner abundance. Increased growth rates may also improve fitness and bolster subsequent spawning stocks. Our research characterized 2 potential ecosystem states, one in which larval sea lamprey benefit from adult conspecifics and another in which the larvae do not.

Manuscript submitted 30 June 2017. Manuscript accepted 8 January 2018. Fish. Bull. 116:142-152 (2018).

Online publication date: 2 February 2018. doi: $10.7755 /$ FB.116.2.3

The views and opinions expressed or implied in this article are those of the author (or authors) and do not necessarily reflect the position of the National Marine Fisheries Service, NOAA.

\title{
The influence of nutrients from carcasses of sea lamprey (Petromyzon marinus) on larval growth and spawner abundance
}

\author{
Daniel M. Weaver (contact author) ${ }^{1}$ \\ Stephen M. Coghlan Jr. ${ }^{1}$ \\ Joseph Zydlewski² \\ Email address for contact author: daniel.weaver@maine.edu \\ 1 Department of Wildlife, Fisheries, and Conservation Biology \\ University of Maine \\ 5755 Nutting Hall \\ Orono, Maine 04469 \\ 2 U.S. Geological Survey \\ Maine Cooperative Fish and Wildlife Research Unit and \\ Department of Wildlife, Fisheries, and Conservation Biology \\ University of Maine \\ 5755 Nutting Hall \\ Orono, Maine 04469
}

Anadromous fish link freshwater and marine ecosystems through the seaward emigration of juveniles and subsequent immigration of adults. These adult fish serve as vectors of marine-derived nutrients into freshwater via metabolic waste, gametes, and the carcasses of dead spawners (Gende et al., 2002; Nislow and Kynard, 2009; Näslund et al., 2015). The resulting nutrients may have a bottom-up effect on freshwater systems through the stimulation of primary and secondary production (Wipfli et al., 2003; Kohler et al., 2008; Weaver et al., 2016). Concurrently, a proportion of liberated nutrients may be assimilated by larval and juvenile fish that reside in freshwater before their migration to the ocean (Lang et al., 2006; Kiernan et al., 2010; Rinella et al., 2012; Weaver, 2017). Unfortunately, dam construction, habitat modification, and overfishing have reduced or eliminated many populations of anadromous fish (Saunders et al., 2006; Sheer and Steel, 2006; Limburg and Waldman, 2009), by severing linkages between freshwater and marine ecosystems. Reduced connectivity diminishes the exchange of energy and nutrients and significantly alters stream food-web structure and productivity (Lamberti et al., 2010). The resulting decrease in adult returns to freshwater systems may, therefore, decrease the supply of nutrients to these systems.

Anadromous populations of sea lamprey, (Petromyzon marinus) subsidize Atlantic coastal freshwater systems during the spring with pulses of marine-derived nutrients (Nislow and Kynard, 2009; Weaver et al., 2015). Sea lamprey spend 1-2 years in the ocean as a top parasitic predator of marine vertebrates (Silva et al., 2014) before migrating into temperate Atlantic coastal freshwater rivers and streams. There they mature, construct nests, spawn, and subsequently die (Beamish, 1980). Their carcasses release marine nutrients to the freshwater environment. During summer, rising water temperatures and increased pho- 
toperiod stimulate primary production and increase the metabolic demand of consumers, including youngof-the-year fish and macro-invertebrates (Hall, 1972; Gustafson-Greenwood and Moring, 1990). The death of sea lamprey and the nutrients from their carcasses can alleviate nutrient limitations of streams and increase productivity to the overall benefit of freshwater communities (Weaver et al., 2016).

Carcasses of sea lamprey may directly benefit conspecifics. After hatching, larval sea lamprey burrow into fine substrate and reside in freshwater as depositfeeding detritivores (Hardisty and Potter, 1971; Evans and Limburg, 2015). In a recent study, Weaver (2017) provided evidence of larval assimilation of nutrients from adult carcasses by documenting enrichment of the ${ }^{13} \mathrm{C}$ isotope among individual fish collected near carcasses. Larval sea lamprey that receive these nutrient subsidies may grow faster than larvae without access to such nutrients. During summer, larvae initiate metamorphosis, a nontrophic period characterized by a series of physical and physiological changes and arrested somatic growth and feeding (Youson, 1980; Youson and Manzon, 2012). After several months, the juveniles (macropthalmia) migrate toward the ocean to begin feeding as parasites (Potter et al., 1978). Thus, the accrual of a surplus of lipids (i.e., energy) during the freshwater larval period is critical for both the developmental "decision" to metamorphose and for the survival and migration of newly metamorphosed lamprey (Lowe et al., 1973).

Freshwater productivity can directly influence growth rates and drive population dynamics of fish populations. Although data that directly link productivity to growth rates are absent for sea lamprey, there is strong evidence of a correlation. The time from the larval period to metamorphosis, for example, has a range of 2-14 years among sea lamprey populations in freshwater of varying productivity (Manion and Smith $^{1}$; Beamish, 1980; Potter, 1980; Purvis, 1980; Beamish et al.2; Morkert et al., 1998; Quintella et al., 2003). Larval growth rates and age at metamorphosis may also be influenced by stream productivity (Potter, 1980; Purvis, 1980; Dawson et al., 2015). Temperature, stream conductivity, and dissolved solids (which are proxies for productivity) were found to be significant predictors of growth rate (Holmes, 1990; Young et al., 1990; Griffiths et al., 2001). Among tributaries in the Great Lakes, the first occurrence of metamorphosis of sea lampreys ranges from age 2 in faster growing populations to age 7 in slower growing populations (Purvis, 1980; Morkert et al., 1998). This variability in

\footnotetext{
${ }^{1}$ Manion, P. J., and B. R. Smith. 1978. Biology of larval and metamorphosing sea lampreys, Petromyzon marinus, of the 1960 year class in the Big Garlic River, Michigan, Part II, 1966-72. Great Lakes Fish. Comm., Tech. Rep.30, 33 p. [Available from website.]

2 Beamish, F. W. H., B. J. Morrison, L. A. Barker, and B. J. Wicks. 1998. Ecology of recruitment in sea lamprey. Great Lakes Fish. Comm., Proj. Compl. Rep. Summ., 22 p. [Available from website.]
}

the duration of the larval period and initiation of metamorphosis may be influenced by the influx of nutrients from the mortality of postspawning adult sea lamprey. This influx, in turn, may create an alternative stable state that reinforces production of spawning adults and promotes population persistence (Kéfi et al., 2016).

We assessed the theoretical influences of carcass nutrients on larval sea lamprey, with the assumption that growth and subsequent metamorphosis of larvae are linked to freshwater productivity. We hypothesize that carcass-mediated productivity may shift the age at which larvae undergo metamorphosis. We used data and values from the literature to construct a heuristic model and probed the sensitivity of various life-history parameters on the growth and metamorphosis of larvae. We compared a hypothesized scenario in which carcass nutrients from adult sea lamprey had no effect on larval growth to a scenario in which increases in productivity mediated by carcasses increased growth. Finally, we explored theoretical effects of changes in metamorphosis on demographic (age) structure of larval populations.

\section{Materials and methods}

\section{Population modeling}

We used data and values of life-history parameters obtained from scientific literature to create a deterministic stock-recruitment model with the software STEL$\mathrm{LA}^{3}$, vers. 10.0.6 (isee systems, Inc., Lebanon, NH). Our model had 3 major parts: 1) a recruitment model; 2) a growth model; and 3) a nutrient feedback model (Fig. 1). The model was designed to capture the entire life history of sea lamprey beginning with larval recruitment in freshwater, metamorphosis and migration to the ocean, ocean survival, migration back to freshwater, and subsequent death and nutrient deposition. We describe 2 populations: one in which larval growth rates are not influenced by returning adult sea lamprey (i.e., unsubsidized populations) and one in which larval growth rates are influenced by returning adult sea lamprey (i.e., subsidized populations).

\section{Recruitment}

We characterized recruitment in early life stages by using a Ricker stock-recruitment relationship (Ricker, 1975; Guy and Brown, 2007). A Ricker curve depicts an increase and then a decrease in larval recruitment with increasing numbers of spawning adults, a relationship that is characteristic of an increasing probability of nest superimposition that may be observed among species that construct nests (e.g., sea lamprey;

\footnotetext{
${ }^{3}$ Mention of trade names or commercial companies is for identification purposes only and does not imply endorsement by the National Marine Fisheries Service, NOAA.
} 


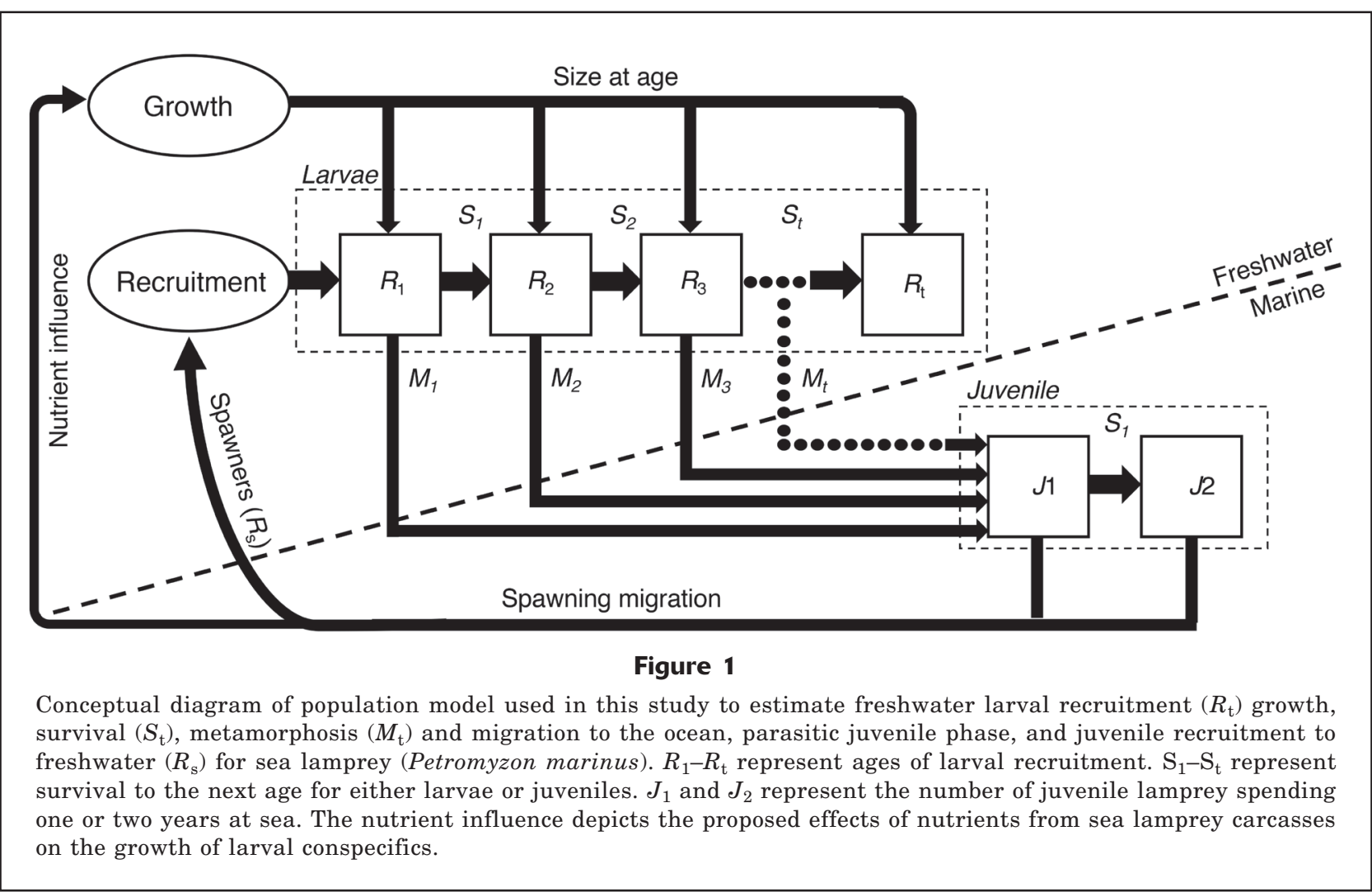

Dawson, 2007; Dawson and Jones, 2009). We defined the recruitment relationship as

$$
R_{\mathrm{t}}=\alpha E e^{-\beta \mathrm{E}},
$$

where $R_{\mathrm{t}}=$ recruitment of larvae at age class $t$;

$E=$ the total number of eggs from female spawners;

$\alpha=$ the slope at the $y$-intercept of the stock recruitment relationship and describes survival at very low levels of $E$; and

$\beta=$ the slope of the stock-recruitment relationship and describes the degree to which survival falls as $E$ increases (i.e., carrying capacity).

We adjusted the $\alpha$ and $\beta$ terms to obtain a stabilized population on the basis of the survival parameters used in the model (Table 1) and the desire to model a realistic carrying-capacity of adult spawners in a small stream (Gardner et al., 2012). We derived a value of $\beta$ iteratively to obtain a stable population size of 4800 spawning adult sea lamprey for an area of suitable spawning habitat of approximately 4.8 ha (1 individu$\mathrm{al} / 10 \mathrm{~m}^{2}$; Nislow and Kynard, 2009), which represents a realistic density of sea lamprey spawners in a thirdorder stream that was not impounded. We assumed an unequal sex ratio of 1.00:1.36 females to males for the total number of spawning adults (Beamish and Potter, 1975; Beamish et al., 1979). The value of $E$ was calculated from the number of females with an average mass of $885.2 \mathrm{~g}$ (Beamish et al., 1979) and $233 \mathrm{eggs} / \mathrm{g}$ of mass (Hardisty, 1971; Table 1).

\section{Freshwater larval growth}

We permitted larvae to remain in freshwater for up to 12 years, which is within the range of the reported development period (Manion and Smith ${ }^{1}$; Beamish, 1980). We modeled growth of larval sea lamprey according to a von Bertalanffy (1938) function, defined as

$$
L_{\mathrm{t}}=L_{\infty}\left(1-e^{-\mathrm{K}\left(\mathrm{t}-\mathrm{t}_{0}\right)}\right),
$$

where $L_{\mathrm{t}}=$ the length of the larvae at time $t$ (years);

$L_{\infty}=$ the theoretical maximum (asymptotic) body length;

$K=$ the Brody growth rate coefficient per year that describes the decline in growth rate as individuals approach $L_{\infty}$; and

$t_{0}=$ the theoretical age at which body length is zero (Guy and Brown, 2007).

We adopted the Ford-Walford method for estimating parameters of the von Bertalanffy growth function (Ford, 1933; Walford, 1946; Isely and Grabowski, 2007) by plotting $L_{\mathrm{t}}$ and $L_{\mathrm{t}+1}$, transforming the von Bertalanffy growth model to follow a linear relation.

We used the plot of $L_{\mathrm{t}}$ and $L_{\mathrm{t}+1}$ to extract the intercept $b$ from linear regressions with different $K$ values ranging from 0.3 to 0.7 , which were selected to represent a range of growth trajectories along a gradient of hypothetical streams of varying productivity. At $K$ 


\section{Table 1}

Settings for recruitment and life-history variables for a model that represents a population of anadromous sea lamprey (Petromyzon marinus).

\begin{tabular}{|c|c|c|}
\hline Variable & Value & Source \\
\hline \multicolumn{3}{|l|}{ Recruitment } \\
\hline$\alpha$ & 0.0014 & Derived from this study \\
\hline$\beta$ & $2.84 \times 10^{-9}$ & Derived from this study \\
\hline$K$ & $0.3-0.7$ & Modified from Quintella et al. (2003) \\
\hline $\operatorname{Eggs}\left(\beta \cdot g \cdot \operatorname{mass}^{-1}\right)$ & 233 & Hardisty (1971) \\
\hline Female adult mass $(\mathrm{g})$ & 885.2 & Beamish et al. (1979) \\
\hline Proportion of females & 0.44 & $\begin{array}{l}\text { Beamish and Potter (1975), } \\
\text { Beamish et al. (1979) }\end{array}$ \\
\hline \multicolumn{3}{|l|}{ Mortality } \\
\hline \multicolumn{3}{|l|}{ Larval mortality $\left(M_{\text {larv }}\right)$} \\
\hline Age 1 & 0.70 & \multirow{6}{*}{$\begin{array}{l}\text { Adopted from Zerrenner (2001), } \\
\text { Howe et al. }{ }^{5}\end{array}$} \\
\hline Age 2 & 0.20 & \\
\hline Age 3 & 0.10 & \\
\hline Age 4 & 0.10 & \\
\hline Age 5 & 0.10 & \\
\hline Ages 6-12 & 0.10 & \\
\hline Metamorphosis $\left(M_{\mathrm{met}}\right)$ & 0.40 & Best guess estimate \\
\hline Juvenile $\left(M_{\text {juv }}\right)$ & 0.40 & $\begin{array}{c}\text { Eshenroder et al. }{ }^{6} \\
\text { Jones et al. (2003); Howe et al. }{ }^{5}\end{array}$ \\
\hline
\end{tabular}

values $<0.3$, simulated larval populations did not reach $L_{\infty}$ within the designated age structure. We capped the range of $K$ at 0.7 , which was observed in larval populations by Quintella et al. (2003) in the Mondego River, Portugal, where larvae grew relatively quickly and achieved metamorphosis at age 4 or younger. We plotted $K$ and $b$ values and then extracted the linear equation to use as an intercept $\left(b_{\mathrm{w}}\right)$ to estimate the length of larvae. We then estimated the body length of an individual at $t+1$ as

$$
L_{\mathrm{t}+1}=L_{\mathrm{t}} e^{-\mathrm{K}+\mathrm{b}_{\mathrm{w}}} .
$$

This method allowed us to manipulate $K$ as a way of representing the influence of nutrient subsidies on larval growth. Estimated values of $K$ obtained from the Ford-Walford plot were calculated as the inverse natural log of the slope. This method approximates but is not identical to those directly derived from the von Bertalanffy growth function (Isely and Grabowski, 2007).

To define the von Bertalanffy growth curve, we used an initial hatching length of $10 \mathrm{~mm}$, a size adopted from 51-d posthatch larvae of Pacific lamprey (Entosphenus tridentatus) (Barron et al., 2016). We found reported total lengths (TLs) of larval sea lamprey before metamorphosis in a range from 120 to $200 \mathrm{~mm}$ (Manion and McLain 4 ; Potter et al., 1978; Quintella et

\footnotetext{
${ }^{4}$ Manion, P. J., and A. L. McLain. 1971. Biology of larval sea lampreys (Petromyzon marinus) of the 1960 year class, isolated in the Big Garlic River, Michigan, 1960-65. Great Lakes Fish. Comm., Tech. Rep.16, 33 p. [Available from website.]
}

al., 2003), and we used a length of $200 \mathrm{~mm}$ TL as the value for $L_{\infty}$. We defined a minimum $K$ value of 0.3 , which served as a baseline value for simulated unsubsidized populations. Subsidized populations had augmented $K$ values that were calculated as a function of the number of returning adult spawners (see Eq. 7 in the Nutrient feedback model section).

We adopted the pattern of estimated annual interval larval mortality at age from Zerrenner (2001), Zerrenner and Marsden, 2005, and Howe et al. ${ }^{5}$ (Table 1) for larval ages 1-12. We calculated larval survival to the next age class with the following equation:

$$
N_{\mathrm{t}+1}=N_{\mathrm{t}}\left(1-M_{\text {larv }}\right)\left(1-P_{\text {met }}\right),
$$

where $N_{\mathrm{t}+1}=$ the number of larvae that are recruited to the $t+1$ age class;

$N_{\mathrm{t}}=$ the number in the current age class;

$M_{\text {larv }}=$ the estimated larval mortality; and

$P_{\text {met }}=$ the proportion of larvae that underwent metamorphosis and migrated out of freshwater.

\section{Probability of metamorphosis}

We modeled larval metamorphosis into the macropthalmic stage by using length and growth data from the

\footnotetext{
${ }^{5}$ Howe, E. A., E. Marsden, and T. M. Donovan. 2004. Stage based population viability model for sea lamprey (Petromyzon marnius). Lake Champlain Basin. Prog., Tech. Rep. 43, 37 p. [Available from website.]
} 
von Bertalanffy growth curve. Larvae that reached 160 $\mathrm{mm}$ TL were considered developed enough to undergo metamorphosis and migrate to the ocean on the basis of the midpoint of the range of lengths at which larvae begin metamorphosis (120-200 mm TL, see previous section). We estimated the number of individuals that underwent metamorphosis of each age class $\left(N_{\text {met }}\right)$ with the following equation:

$$
N_{\text {met }}=N_{\mathrm{t}}\left(1-M_{\text {larv }}\right) P_{\text {met }}\left(1-M_{\text {met }}\right),
$$

where $P_{\text {met }}=$ the probability of metamorphosis; and

$M_{\text {met }}=$ the mortality associated with metamorphosis and migration to the ocean. $M_{\text {met }}$ is poorly characterized (Hansen et al., 2016) but, for our purposes, was designated as 0.4 for individuals of all age classes.

\section{Juvenile demographics}

Juvenile sea lamprey typically spend 1-2 years at sea (Beamish, 1980). We calculated the number of juveniles spending a second year in the ocean as

$$
J_{2}=J_{1}\left(1-M_{\text {juv }}\right)\left(1-P_{\text {mat }}\right),
$$

where $J_{2}=$ the number of juveniles recruited to a second year at sea;

$J_{1}=$ the number of juveniles that have completed a full year at sea;

$M_{\text {juv }}=$ the estimated juvenile mortality; and

$P_{\text {mat }}=$ the proportion of individuals recruiting to maturity and returning to freshwater to spawn.

We calculated $M_{\text {juv }}$ to be 0.40 , by averaging estimates of survivorship of juvenile to adult spawners in the Great Lakes (Eshenroder et al.6; Jones et al., 2003; Howe et al. ${ }^{5}$; Table 1 ). We designated probabilities associated with juvenile $P_{\text {mat }}$ after 1 and 2 years at sea as 0.5 and 1.0 , respectively.

\section{Nutrient feedback model}

Carcasses of postspawn sea lamprey deposit organic carbon and inorganic nitrogen and phosphorous in freshwater streams (Weaver et al., 2015), and such deposits have been reported to influence stream productivity (Weaver et al., 2016). To test the effect of a hypothetical influence of carcass nutrients on larval growth, we allowed the Brody growth coefficient $K$, to vary as a function of the number of carcasses deposited in freshwater. This estimate of $K$ served as a representation of the influence of organic and inorganic nutrients. Although $K$ is a growth coefficient (which represents the rate at which growth slows as larvae approach $L_{\infty}$ ) and not a growth rate per se, we used it as a proxy for pro-

\footnotetext{
${ }^{6}$ Eshenroder, R. L., R. A. Bergstedt, D. W. Cuddy, G. W. Fleischer, C. K. Minns, T. J. Morse, N. R. Payne, and R. G. Schorfhaar. 1987. Great Lakes Fishery Commission Report of the St. Marys River Sea Lamprey Task Force, 35 p. [Available from website.]
}

ductivity-mediated growth rate because $L_{\infty}$ is held constant. Therefore, higher values of $K$ mean individuals reach their maximum length sooner. We hypothesized that a nutrient feedback mediated through additions to the value of $K$ would have a peak effect (an inflection point) followed by diminishing returns as the addition of carcasses increased. This relationship has been postulated or shown for many ecological systems (Kéfi et al., 2016) and effectively described with a logistic regression. During model simulations of populations receiving nutrient feedbacks, we assumed $K$ values followed a logistic regression:

$$
K=0.3+1 /\left(1+e^{-\left(\gamma+\delta \mathrm{TS}_{\mathrm{t}}\right)}\right)
$$

where $\gamma$ and $\delta=$ parameters that influence how steeply the logistic function rises through a midpoint and the duration at which the midpoint occur, and

$T S_{\mathrm{t}}=$ the total number of adults returning to freshwater streams at year $t$.

Calculated values from the logistic equation were added to the baseline $K$ value of 0.3 to depict the adjustment in growth rate for larvae in subsidized populations.

\section{Model execution}

We initially populated each larval and juvenile age class with arbitrary values and ran the unsubsidized model for 200 years, which served as a burn-in period to allow the population to stabilize. We took the final numbers of each larval and juvenile age class and reseeded the starting model with those values. We estimated our unsubsidized population size at the point at which abundance remained constant over a 200-year period. We then reran the model with larval growth influenced by the number of returning adult spawners as reflected by varying values of $K$ (Eq. 7) and examined the resulting changes in demographics for the subsidized population.

\section{Model sensitivity}

We gauged the local sensitivity of mortality, $M_{\text {larv }}$, $M_{\text {met }}, M_{\text {juv }}$; the parameters $\alpha, \beta$, and $K$ of unsubsidized populations; and the $\gamma$ and $\delta$ logistic regression parameters for manipulating $K$ in subsidized populations. We applied a $1 \%$ increase in selected parameters on the number of total spawners in the stabilized population. Sensitivity $(S)$ of parameters for number of total spawners was calculated as

$$
S=\frac{\left(R_{\mathrm{a}}-R_{\mathrm{n}}\right) / R_{\mathrm{n}}}{\left(P_{\mathrm{a}}-P_{\mathrm{n}}\right) / P_{\mathrm{n}}}
$$

where $R_{\mathrm{a}}=$ the result for the altered variable;

$R_{\mathrm{n}}=$ the result for the unaltered variable;

$P_{\mathrm{a}}=$ the altered parameter; and

$P_{\mathrm{n}}=$ the nominal parameter (Haefner, 2005; Bailey and Zydlewski, 2013).

Model output was deemed "sensitive" to the parameter if $|S|>1.00$. 

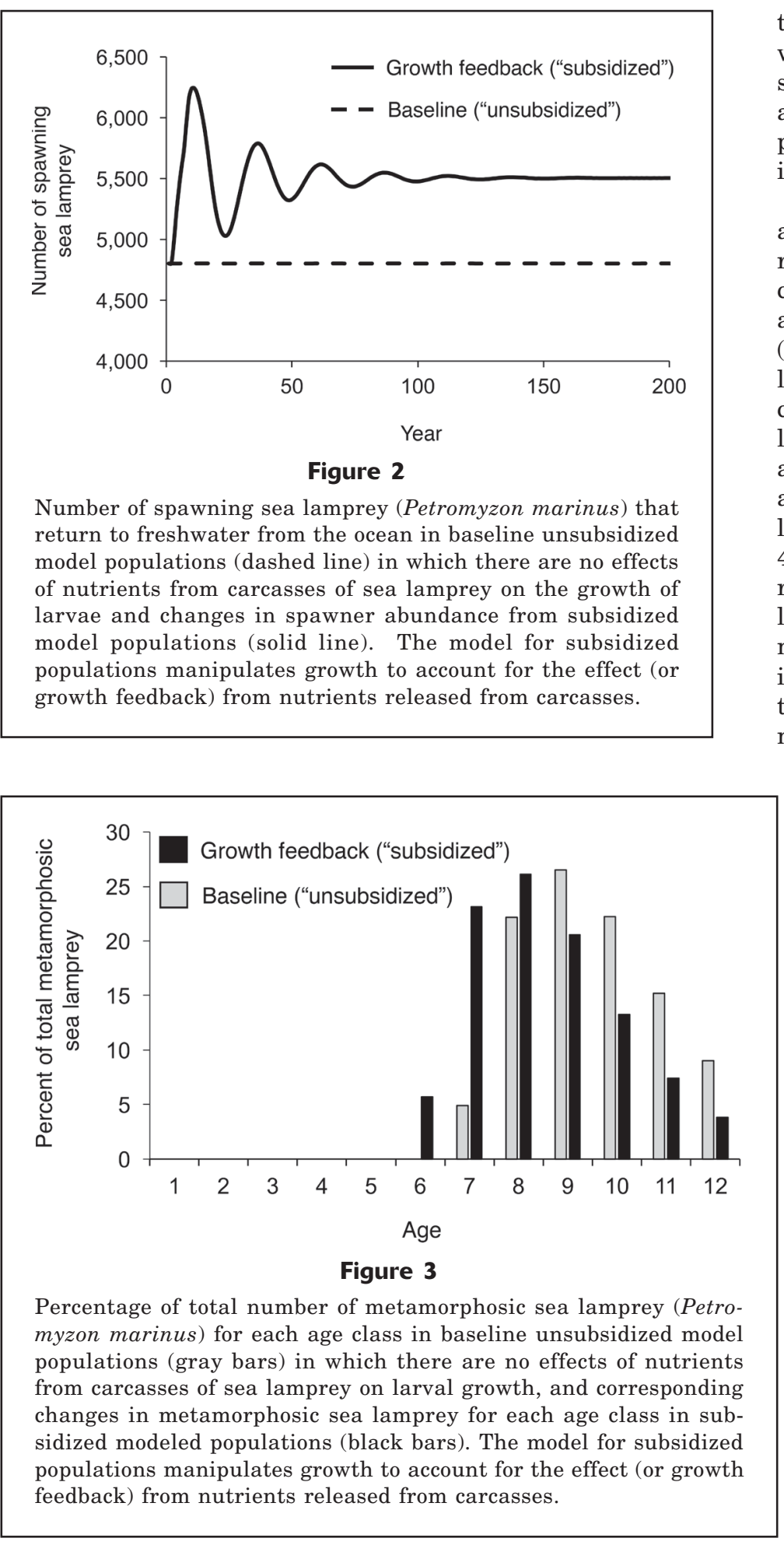

\section{Results}

The population model was adjusted to simulate unsubsidized populations of total spawners at approximately 4800 individuals (Fig. 2), which is a reasonable estimate of spawner carrying capacity in a small, third-order stream. This number was used as the starting popula- tion for the simulation of subsidized populations with the incorporation of growth feedback. Subsidized populations of total spawners were variable for 100 years, then began to stabilize at a population size of approximately 5500 individuals, indicating a $12 \%$ increase in adult returns (Fig. 2).

We simulated changes in the distribution of age classes when larvae achieved higher growth rates from the input of nutrients from adult carcasses. When we assumed no feedback, $>95 \%$ of all metamorphosed larvae were 8 years or older (Fig. 3). When we assumed nutrient feedback, larval populations shifted toward younger age classes. Approximately $30 \%$ of all metamorphosed larvae were younger than 8 years. The shifts in age at metamorphosis toward younger individuals correspond with the manipulations of age at length in the Von Bertalanffy growth model (Fig. 4). Results from the model indicate higher growth rates among the subsidized populations that allowed larvae to reach the minimum length at metamorphosis (160 mm TL) at an earlier age in contrast with results for unsubsidized populations that reached the minimum length at metamorphosis at relatively older ages.

The results of our sensitivity analysis indicated that age-1 larval mortality was relatively sensitive to change $(|S|>1.00$; Table 2). Generally, we found that increases in larval mortality resulted in lower returns of adult spawners and, conversely, that reduced larval mortality resulted in increases in the number of total spawners. Total modeled spawner abundance was inversely influenced by increases in mortality related to larval metamorphosis and the juvenile phase in the ocean; however, these parameters were less sensitive to change. Consistent with the role of the 2 constants in the Ricker function, $\alpha$ was positively associated with larval recruitment and $\beta$, which delineates carrying capacity, was negatively related. Neither of these parameters was deemed sensitive on the basis of our a priori sensitivity threshold (1.00), although both sensitivities approached the measure. Among subsidized populations, we found that changes in $\gamma$ and $\delta$ parameters resulted in larger annual fluctuations in the number of total spawners and potentially prolonged the time necessary for populations to stabilize, but we did not find these parameters to be highly sensitive with respect to spawner abundance in the stabilized population.

\section{Discussion}

We constructed a deterministic model to illustrate the complex life history of sea lamprey, and the manipula- 


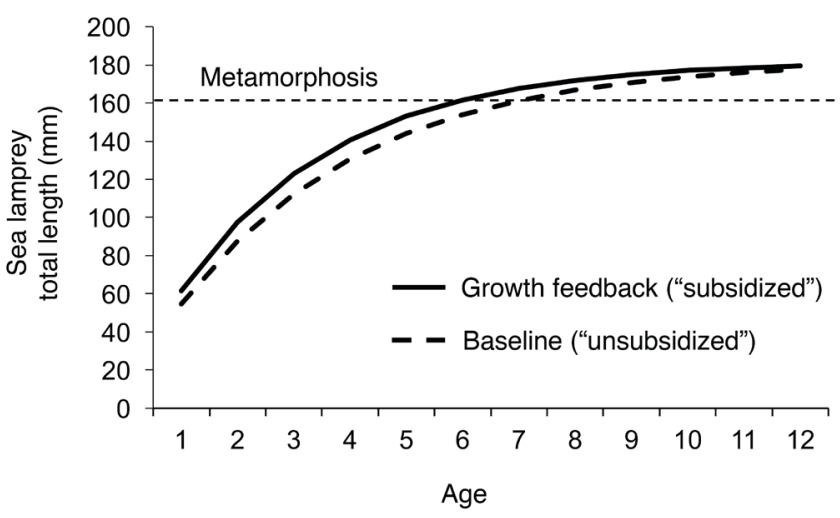

Figure 4

Age at length of larval sea lamprey (Petromyzon marinus) from a modeled von Bertalanffy growth curve in baseline unsubsidized model populations (dashed line) in which there are no effects of nutrients from carcasses of sea lamprey on the growth of larvae and changes in age at length in subsidized model populations (solid line). The model for subsidized populations manipulates growth to account for the effect (or growth feedback) from nutrients released from carcasses.

\section{Table 2}

Sensitivity $(S)$ of the total number of returning, spawning sea lamprey (Petromyzon marinus) determined from stabilized model runs to a $1 \%$ increase in model parameters. Variables include larval mortality at age $\left(M_{\text {larv }}\right)$, mortality at metamorphosis and time of migration to the ocean $\left(M_{\text {met }}\right)$, juvenile mortality $\left(M_{\text {juv }}\right), \alpha$ and $\beta$ parameters of the Ricker stock-recruitment relationship, and $\gamma$ and $\delta$ logistic growth parameters of the nutrient feedback model. $|S|$ values above 1.00 were deemed sensitive and are indicated in bold.

\begin{tabular}{lccc}
\hline Parameter & & Nominal value & $S$ \\
\hline Recruitment & $\alpha$ & 0.0014 & 0.833 \\
Mortality & $\beta$ & $2.84 \times 10^{-9}$ & -0.958 \\
& $M_{\text {larv1 }}$ & 0.74 & $\mathbf{- 1 . 8 9 5}$ \\
& $M_{\text {larv2 }}$ & 0.07 & -0.208 \\
& $M_{\text {larv3 }}$ & 0.05 & -0.062 \\
& $M_{\text {larv4 }}$ & 0.09 & -0.062 \\
& $M_{\text {larv5 }}$ & 0.12 & -0.062 \\
& $M_{\text {larv6 }}$ & 0.10 & -0.062 \\
& $M_{\text {larv7 }}$ & 0.10 & -0.062 \\
& $M_{\text {larv8 }}$ & 0.10 & -0.062 \\
& $M_{\text {larv9 }}$ & 0.10 & -0.062 \\
& $M_{\text {larv10 }}$ & 0.10 & -0.042 \\
& $M_{\text {larv11 }}$ & 0.10 & 0 \\
& $M_{\text {larv12 }}$ & 0.10 & 0 \\
& $M_{\text {met }}$ & 0.60 & -0.521 \\
& $M_{\text {juv }}$ & 0.413 & -0.708 \\
Logistic growth & $\gamma$ & -4.0 & -0.563 \\
& $\delta$ & $1.0 \times 10^{-4}$ & 0.273 \\
& $\delta$ & & \\
\hline & & &
\end{tabular}

tion of model parameters allowed us to explore potential nutrient feedbacks between freshwater and marine ecosystems. Previous research has shown increases in freshwater productivity from carcasses of sea lamprey and assimilation of carcass nutrients by larval conspecifics (Weaver et al., 2016; Weaver, 2017). Results from our model indicate the potential role of carcass nutrients in stimulating larval growth and lowering the age at metamorphosis as a result of higher productivity. This model clearly illustrates the critical importance of nutrient exchange among anadromous fish between freshwater and marine systems, an exchange that is likely to result in populationlevel changes.

We hypothesized that recruitment dynamics of sea lamprey are driven by changes in in-stream primary production, but recruitment may also be shaped by density-dependent factors (e.g., prey abundance and competition; Klanderud, 2010), independent processes (e.g., temperature or flow; Tonkin et al., 2017), or a combination of both (Jónsdóttir et al., 2013). Juvenile sea lamprey in the ocean function as parasitic predators and their successful recruitment may, therefore, respond to an additional suite of biotic and abiotic factors, including less obvious factors related to the population dynamics of their hosts.

We show that changes in productivity may influence population demography, but other life-history attributes may be affected as well. For example, the sex-ratio of larval populations in more productive waters may become skewed toward females (Johnson et al., 2017), a shift that conceivably is a result of the addition and availability of carcass nutrients. Furthermore, one male may mate with several females (Beamish, 1980; Gardner et al., 2012), and recruitment dynamics may be further influenced by populations that are subsidized by carcass nutrients. Results from our model also indicate that population demographics may have an even farther reaching influence that could extend to other species and across ecosystems. High densities of larval sea lamprey may reduce individual growth rates and survival and extend the duration of the larval period and hence delay metamorphosis (Morman, 1987; Murdoch et al., 1992). Established populations that are at or near carrying capacity likely experience slower growth that is reflective of limited resources. Conversely, low densities of larvae, characteristic of populations facing impaired migratory access and thus fewer adult returns, may show higher growth rates among all cohorts (Purvis7; Torblaa and Westman, 1980; Morman, 1987). Models that do not account for density-dependent growth may not accurately capture associated

\footnotetext{
7 Purvis, H. A. 1979. Variations in growth, age at transformation, and sex ratio of sea lampreys reestablished in chemically treated tributaries of the upper Great Lakes. Great Lakes Fish. Comm., Tech. Rep.35, 36 p. [Available from website.]
} 
changes in population dynamics, including the recovery or re-establishment of fish populations (e.g., salmonids; Vincenzi et al., 2012).

We assumed that the addition of nutrients from mortality of postspawning adult sea lamprey (i.e., changes in productivity) influences the variability associated with growth and metamorphosis of larval sea lamprey. In reality, larval metamorphosis is dependent upon many different biological factors (e.g., lipid accrual; Lowe et al., 1973) and variation in environmental conditions that extend beyond productivity alone. Some of these factors have been thoroughly explored among other anadromous fish, especially salmonids, and may have implications for population demographics and persistence of sea lamprey. Anadromous salmon parr, for example, grow in freshwater before becoming smolts, a process characterized by a series of energetically demanding physical and physiological changes (McCormick et al., 1997). Research has shoen that higher water temperatures provide parr with more opportunities for growth, up to an optimal temperature after which growth is likely reduced, and this growth may result in earlier smoltification (Zaugg and McLain, 1976; Thorpe et al., 1989). Nutrients from carcasses of sea lamprey stimulate productivity during spring, a critical period of temperature-driven increases in metabolism for fish facing potential limitations in resources (Hall, 1972; Weaver et al., 2015; Weaver et al., 2016). Therefore, salmon parr that are subsidized directly and indirectly by these resources may benefit from a compensatory growth as fish approach the smolt stage (Guyette et al., 2013; Sigourney et al., 2013). This enhanced growth could potentially increase survival and reduce the number of years spent in freshwater before the young salmon successfully migrate to the ocean (Horton et al., 2009). Weaver (2017) showed nutrient assimilation of carcasses of adult sea lamprey by larval conspecifics, but because it has not yet been documented that carcasses contribute to larval growth, this process remains an important area for future study.

Many of the parameters used in our model are poorly documented in the scientific literature. Our model run for the unsubsidized, stabilized population was sensitive to several life-history and recruitment parameters. We used a sensitivity analysis to bracket what would be realistic values, with age- 1 mortality being the most sensitive parameter among the tested variables. Population dynamics are largely governed by 3 demographic processes: recruitment, growth, and mortality (Hilborn and Walters, 1992), and results from our sensitivity analysis indicate that small changes in these processes can have substantial effects on both recruitment and the returning populations of spawning sea lamprey. Furthermore, the short-term dynamics of the model output are driven by the assumptions with using the Ricker curve, which may or may not accurately reflect the biology of sea lamprey. Other recruitment curves (e.g., the Beverton-Holt) may be biologically more realistic, but the long-term dynamics and stable states achieved do not differ. The results of our model- ing highlight the need for more detailed life-history information for anadromous fish species like sea lamprey.

Anadromous sea lamprey are native to Atlantic coastal waters and are an important driver of nutrient cycling (Weaver et al., 2016). However, sea lamprey have garnered notoriety from their invasion into the Laurentian Great Lakes and their contribution to the decimation of native fish populations and altered food webs (Applegate, 1950; Bronte et al., 2003; Ricciardi, 2006; Great Lakes Fishery Commission ${ }^{8}$ ). Anadromous and landlocked populations exhibit similar life-history strategies, but the ecological implications have invoked differing fisheries management actions. Our modeling exercise was framed in the context of conserving anadromous Atlantic coastal populations, but these results may also have important implications for the way in which sea lamprey are managed in other systems. Sea lamprey in the landlocked Great Lakes are managed as a pest species, and recruitment dynamics may be influenced by the types of eradication and control methods used (Jones, 2007; Dawson and Jones, 2009). However, generally speaking, managers attempt to control invasive species with limited knowledge of their life history (Simberloff, 2003). A more complete understanding of the population dynamics of a species is critical for both population conservation and control strategies (Great Lakes Fishery Commission ${ }^{8}$ ). Our model is based on the hypothesis that nutrients from carcasses of sea lamprey increase larval growth rates and enhance earlier metamorphosis. This hypothesis is consistent with research in the Great Lakes, indicating that more productive waters contain faster growing larvae that reach metamorphosis at younger ages (Purvis, 1980; Morkert et al., 1998; Griffiths et al., 2001). Therefore, predictive models used for management and control measures of larval sea lamprey (Treble et al., 2008) may be more accurate with the incorporation of demographic shifts in populations of sea lamprey. The results from our model indicate the consequences of potential feedback mechanisms that may be relevant to decisions regarding management actions to conserve and restore ecosystem functions or control and eradicate an invasive species.

Currently, the focus of natural resource management has shifted toward ecosystem restoration (Palmer et al., 2014). Our model closes the hypothesized nutrient loop, and results from our model indicate a feedback process by which nutrients from carcasses of sea lamprey influence spawning stocks by subsidizing growth that may improve larval fitness (Hall, 1972; Hall et al., 1992). Globally, many anadromous fish species are threatened or imperiled (Limburg and Waldman, 2009) and our results indicate that current management strategies may need to consider energy and nutrient exchanges between ecosystems and the effects of these

\footnotetext{
${ }^{8}$ Great Lakes Fishery Commission. 2011. Strategic vision of the Great Lakes Fishery Commission 2011-2020. Great Lakes Fish. Comm., Misc. Publ. 2011-13, 29 p. [Available from website.]
} 
exchanges on the life-history stages of the associated species. Broadly, our work highlights the importance of identifying and describing ecological functions among species that link multiple ecosystems.

\section{Acknowledgments}

This work is based on research supported in part by Hatch grant ME0-8367-0H from the U.S. Department of Agriculture and the Department of Wildlife, Fisheries, and Conservation Biology of the University of Maine (Maine Agriculture and Forest Experiment Station Publication Number 3576). Logistical support was provided by the U.S. Geological Survey Maine Cooperative Fish and Wildlife Research Unit. Any use of trade, firm, or product names is for descriptive purposes only and does not imply endorsement by the U.S. Government.

\section{Literature cited}

Applegate, V. C.

1950. Natural history of the sea lamprey (Petromyzon marinus) in Michigan. U.S. Fish Wildl. Serv., Spec. Sci. Rep.: Fish. Ser. No. 55, 230 p.

Bailey, M. M., and J. D. Zydlewski.

2013. To stock or not to stock? Assessing the restoration potential of a remnant American shad spawning run with hatchery supplementation. North Am. J. Fish. Manage. 33:459-467. Article

Barron, J. M., R. G. Twibell, H. A. Hill, K. C. Hanson, and A.

L. Gannam.

2016. Development of diets for the intensive culture of Pacific lamprey. Aquac. Res. 47:3899-3906. Article

Beamish, F. W. H.

1980. Biology of the North American anadromous sea lamprey, Petromyzon marinus. Can. J. Fish. Aquat. Sci. 37:1924-1943. Article

Beamish, F. W. H., and I. C. Potter.

1975. The biology of the anadromous sea lamprey (Petromyzon marinus) in New Brunswick. J. Zool. 177:57-72. Article

Beamish, F. W. H., I. C. Potter, and E. Thomas.

1979. Proximate composition of the adult anadromous sea lamprey, Petromyzon marinus, in relation to feeding, migration and reproduction. J. Anim. Ecol. 48:1-19. Article

Bronte, C. R., M. P. Ebener, D. R. Schreiner, D. S. DeVault, M. M. Petzold, D. A. Jensen, C. Richards, and S. J. Lozano. 2003. Fish community change in Lake Superior, 19702000. Can. J. Fish. Aquat. Sci. 60:1552-1574. Article

Dawson, H. A.

2007. Recruitment dynamics of Great Lakes sea lamprey (Petromyzon marinus) populations and implications for integrated pest management. Ph.D. diss., 106 p. Michigan State Univ., East Lansing, MI.

Dawson, H. A., and M. L. Jones.

2009. Factors affecting recruitment dynamics of Great Lakes sea lamprey (Petromyzon marinus) populations. J. Great Lakes Res. 35:353-360. Article
Dawson, H. A., B. R. Quintella, P. R. Almeida, A. J. Treble, and J. C. Jolley.

2015. The ecology of larval and metamorphosing lampreys. In Lampreys: biology, conservation, and control (M. F. Docker, ed.), p. 75-137. Springer, Dordrecht, Netherlands.

Evans, T. M., and K. E. Limburg.

2015. The distribution of larval sea lampreys, Petromyzon marinus, and their nutritional sources in the Hudson River basin. Northeastern Nat. 22:69-83.

Ford, E.

1933. An account of the herring investigations conducted at Plymouth during the years from 1924 to 1933 . J. Mar. Biol. Assoc. U.K. 19:305-384. Article

Gardner, C., S. M. Coghlan Jr., and J. Zydlewski.

2012. Distribution and abundance of anadromous sea lamprey spawners in a fragmented stream: current status and potential range expansion following barrier removal. Northeastern Nat. 19:99-110.

Gende, S. M., R. T. Edwards, M. F. Willson, and M. S. Wipfli. 2002. Pacific salmon in aquatic and terrestrial ecosystems: Pacific salmon subsidize freshwater and terrestrial ecosystems through several pathways, which generates unique management and conservation issues but also provides valuable research opportunities. BioScience 52:917-928. Article

Griffiths, R. W., F. W. H. Beamish, B. J. Morrison, and L. A. Barker.

2001. Factors affecting larval sea lamprey growth and length at metamorphosis in lampricide-treated streams. Trans. Am. Fish. Soc. 130:289-306. Article

Gustafson-Greenwood, K. I., and J. R. Moring.

1990. Territory size and distribution of newly-emerged Atlantic salmon (Salmo salar). Hydrobiologia 206:125-131. Article

Guy, C. S., and M. L. Brown (eds.).

2007. Analysis and interpretation of freshwater fisheries data, 961 p. Am. Fish. Soc., Bethesda, MD.

Guyette, M. Q., C. S. Loftin, and J. Zydlewski.

2013. Carcass analog addition enhances juvenile Atlantic salmon (Salmo salar) growth and condition. Can. J. Fish. Aquat. Sci. 70:860-870. Article

Haefner, J. W.

2005. Modeling biological systems: principles and applications, $2^{\text {nd }}$ ed., 475 p. Springer Science+Business Media, Inc., New York.

Hall, C. A. S.

1972. Migration and metabolism in a temperate stream ecosystem. Ecology 53:585-604. Article

Hall, C. A. S., J. A. Stanford, and F. R. Hauer.

1992. The distribution and abundance of organisms as a consequence of energy balances among multiple environmental gradients. Oikos 65:377-390. Article

Hansen, M. J., C. P. Madenjian, J. W. Slade, T. B. Steeves, P. R. Almeida, B. R. Quintella.

2016. Population ecology of the sea lamprey (Petromyzon marinus) as an invasive species in the Laurentian Great Lakes and an imperiled species in Europe. Rev. Fish Biol. Fish. 26:509-535. Article

Hardisty, M. W.

1971. Gonadogenesis, sex differentiation and gametogenesis. In The biology of lampreys, vol. 1 (M. W. Hardisty and I.C. Potter, eds.), p. 295-359. Academic Press, London. 
Hardisty, M. W., and I. C. Potter.

1971. The behavior, ecology and growth of larval lampreys. In The biology of lampreys, vol. 1 (M. W. Hardisty and I. C. Potter, eds.), p. 85-125. Academic Press, London.

Hilborn, R., and C. J. Walters (eds.).

1992. Quantitative fisheries stock assessment: choice, dynamics and uncertainty, 570 p. Routledge, Chapman \& Hall, Inc., New York.

Holmes, J. A.

1990. Sea lamprey as an early responder to climate change in the Great Lakes Basin. Trans. Am. Fish. Soc. 119:292-300. Article

Horton, G. E., B. H. Letcher, M. M. Bailey, and M. T. Kinnison. 2009. Atlantic salmon (Salmo salar) smolt production: the relative importance of survival and body growth. Can. J. Fish. Aquat. Sci. 66:471-483. Article

Isely, J. J., and T. B. Grabowski.

2007. Age and growth. In Analysis and interpretation of freshwater fisheries data (C.S. Guy and M.L. Brown, eds.), p. 187-228. Am. Fish. Soc., Bethesda, MD.

Johnson, N. S., W. D. Swink, and T. O. Brenden.

2017. Field study suggests that sex determination in sea lamprey is directly influenced by larval growth rate. Proc. R. Soc., B 284:20170262. Article

Jones, M. L.

2007. Toward improved assessment of sea lamprey population dynamics in support of cost-effective sea lamprey management. J. Great Lakes Res. 33:35-47. Article

Jones, M. L., R. A. Bergstedt, M. B. Twohey, M. F. Fodale, D. W. Cuddy, and J. W. Slade.

2003. Compensatory mechanisms in Great Lakes sea lamprey populations: implications for alternative control strategies. J. Great Lakes Res. 29:113-129. Article

Jónsdóttir, I. G., A. Magnússon, and U. Skúladóttir.

2013. Influence of increased cod abundance and temperature on recruitment of northern shrimp (Pandalus borealis). Mar. Biol. 160:1203-1211. Article

Kéfi, S., M. Holmgren, and M. Scheffer.

2016. When can positive interactions cause alternative stable states in ecosystems? Funct. Ecol. 30:88-97. Article

Kiernan, J. D., B. N. Harvey, and M. L. Johnson.

2010. Direct versus indirect pathways of salmon-derived nutrient incorporation in experimental lotic food webs. Can. J. Fish. Aquat. Sci. 67:1909-1924. Article

Klanderud, K.

2010. Species recruitment in alpine plant communities: the role of species interactions and productivity. J. Ecol. 98:1128-1133. Article

Lamberti, G. A., D. T. Chaloner, and A. E. Hershey.

2010. Linkages among aquatic ecosystems. J. North Am. Benthol. Soc. 29:245-263. Article

Lang, D. W., G. H. Reeves, J. D. Hall, and M. S. Wipfli.

2006. The influence of fall-spawning coho salmon (Oncorhynchus kisutch) on growth and production of juvenile coho salmon rearing in beaver ponds on the Copper River Delta, Alaska. Can. J. Fish. Aquat. Sci. 63:917-930. Article

Limburg, K. E., and J. R. Waldman.

2009. Dramatic declines in North Atlantic diadromous fishes. BioScience 59:955-965. Article

Lowe, D. R., F. W. H. Beamish, and I. C. Potter.

1973. Changes in proximate body composition of landlocked sea lamprey Petromyzon marinus (L.) during lar- val life and metamorphosis. J. Fish Biol. 5:673-682. Article

McCormick, S. D., J. M. Shrimpton, and J. Zydlewski.

1997. Temperature effects on osmoregulatory physiology of anadromous fish. In Global warming: implications for freshwater and marine fish (C.M. Wood and D.G. McDonald, eds.), p. 279-301. Cambridge Univ. Press, Cambridge, UK.

Morkert, S. B., W. D. Swink, and J. G. Seelye.

1998. Evidence for early metamorphosis of sea lampreys in the Chippewa River, Michigan. North Am. J. Fish. Manage. 18:966-971. Article

Morman, R. H.

1987. Relationship of density to growth and metamorphosis of caged larval sea lampreys, Petromyzon marinus Linnaeus, in Michigan streams. J. Fish Biol. 30:173181. Article

Murdoch, S. P., M. F. Docker, and F. W. H. Beamish.

1992. Effect of density and individual variation on growth of sea lamprey (Petromyzon marinus) larvae in the laboratory. Can. J. Zool. 70:184-188. Article

Näslund, J., D. Aldvén, and L. Závorka.

2015. Eggs from anadromous adults provide marine-derived nutrients to Atlantic salmon and brown trout parr in late autumn-observations from a Swedish coastal stream. Environ. Biol. Fish. 98:2305-2313. Article

Nislow, K. H., and B. E. Kynard.

2009. The role of anadromous sea lamprey in nutrient and material transport between marine and freshwater environments. Am. Fish. Soc. Symp. 69:485-494.

Palmer, M. A., K. L. Hondula, and B. J. Koch.

2014. Ecological restoration of streams and rivers: shifting strategies and shifting goals. Annu. Rev. Ecol. Evol. Syst. 45:247-269. Article

Potter, I. C

1980. Ecology of larval and metamorphosing lampreys. Can. J. Fish. Aquat. Sci. 37:1641-1657. Article

Potter, I. C., G. M. Wright, and J. H. Youson.

1978. Metamorphosis in the anadromous sea lamprey, Petromyzon marinus L. Can. J. Zool. 56:561-570. Article

Purvis, H. A.

1980. Effects of temperature on metamorphosis and the age and length at metamorphosis in sea lamprey (Petromyzon marinus) in the Great Lakes. Can. J. Fish. Aquat. Sci. 37:1827-1834. Article

Quintella, B. R., N. O. Andrade, and P. R. Almeida.

2003. Distribution, larval stage duration and growth of the sea lamprey ammocoetes, Petromyzon marinus L., in a highly modified river basin. Ecol. Freshw. Fish. 12:286-293. Article

Ricciardi, A.

2006. Patterns of invasion in the Laurentian Great Lakes in relation to changes in vector activity. Divers. Distrib. 12:425-433. Article

Ricker, W. E.

1975. Computation and interpretation of biological statistics of fish populations. Bull. Fish. Res. Board Can. $191,382 \mathrm{p}$

Rinella, D. J., M. S. Wipfli, C. A. Stricker, R. A. Heintz, and M. J. Rinella.

2012. Pacific salmon (Oncorhynchus spp.) runs and consumer fitness: growth and energy storage in stream-dwelling salmonids increase with salmon spawner density. Can J. Fish. Aquat. Sci. 69:73-84. Article 
Saunders, R., M. A. Hachey, and C. W. Fay.

2006. Maine's diadromous fish community: past, present, and implications for Atlantic salmon recovery. Fisheries 31:537-547. Article

Sheer, M. B., and E. A. Steel.

2006. Lost watersheds: barriers, aquatic habitat connectivity, and salmon persistence in the Willamette and Lower Columbia River basins. Trans. Am. Fish. Soc. 135:16541669. Article

Sigourney, D. B., B. H. Letcher, M. Obedzinski, and R. A. Cunjak.

2013. Interactive effects of life history and season on sizedependent growth in juvenile Atlantic salmon. Ecol. Freshw. Fish 22:495-507. Article

Silva, S., M. J. Araújo, M. Bao, G. Mucientes, and F. Cobo.

2014. The haematophagous feeding stage of anadromous populations of sea lamprey Petromyzon marinus: low host selectivity and wide range of habitats. Hydrobiologia 734:187-199. Article

Simberloff, D.

2003. How much information on population biology is needed to manage introduced species? Conserv. Biol. 17:83-92. Article

Thorpe, J. E., C. E. Adams, M. S. Miles, and D. S. Keay.

1989. Some influences of photoperiod and temperature on opportunity for growth in juvenile Atlantic salmon, Salmo salar L. Aquaculture 82:119-126. Article

Tonkin, Z., J. Kearns, J. Lyon, S. R. Balcombe, A. J. King, and N. R. Bond.

2017. Regional-scale extremes in river discharge and localized spawning stock abundance influence recruitment dynamics of a threatened freshwater fish. Ecohydrology 10:e1842. Article

Torblaa, R. L., and R. W. Westman.

1980. Ecological impacts of lampricide treatments on sea lamprey (Petromyzon marinus) ammocoetes and metamorphosed individuals. Can. J. Fish. Aquat. Sci. 37:18351850. Article

Treble, A. J., M. L. Jones, and T. B. Steeves.

2008. Development and evaluation of a new predictive model for metamorphosis of Great Lakes larval sea lamprey (Petromyzon marinus) populations. Journal of Great Lakes Research 34:404-417. Article

Vincenzi, S., W. H. Satterhwaite, and M. Mangel.

2012. Spatial and temporal scale of density-dependent body growth and its implications for recruitment, population dynamics and management of stream-dwelling salmonid populations. Rev. Fish Biol. Fish. 22:813-825. Article von Bertalanffy, L.

1938. A quantitative theory of organic growth (inquiries on growth laws. II). Hum. Biol. 10:181-213.

Walford, L. A.

1946. A new graphic method of describing the growth of animals. Biol. Bull. 90:141-147. Article

Weaver, D. M.

2017. Sea lamprey (Petromyzon marinus) as a functional link between marine and freshwater ecosystems. Ph.D. diss., 148 p. Univ. Maine, Orono, ME.

Weaver, D. M., S. M. Coghlan Jr., J. Zydlewski, R. S. Hogg, and M. Canton.

2015. Decomposition of sea lamprey Petromyzon marinus carcasses: temperature effects, nutrient dynamics, and implications for stream food webs. Hydrobiologia 760:57-67. Article

Weaver, D. M., S. M. Coghlan Jr., and J. Zydlewski.

2016. Sea lamprey carcasses exert local and variable food web effects in a nutrient-limited Atlantic coastal stream. Can. J. Fish. Aquat. Sci. 73:1616-1625. Article

Wipfli, M. S., J. P. Hudson, J. P. Caouette, and D. T. Chaloner.

2003. Marine subsidies in freshwater ecosystems: salmon carcasses increase the growth rates of stream-resident salmonids. Trans. Am. Fish. Soc. 132:371-381. Article

Young, R. J., J. R. M. Kelso, and J. G. Weise.

1990. Occurrence, relative abundance, and size of landlocked sea lamprey (Petromyzon marinus) ammocoetes in relation to stream characteristics in the Great Lakes. Can. J. Fish. Aquat. Sci. 47:1773-1778. Article

Youson, J. H.

1980. Morphology and physiology of lamprey metamorphosis. Can. J. Fish. Aquat. Sci. 37:1687-1710. Article Youson, J. H., and R. G. Manzon.

2012. Lamprey metamorphosis. In Metamorphosis in fish (S. Dufour, K. Rousseau, and B. G. Kapoor, eds.), p. 12-75. Science Publishers, Enfield, NH.

Zaugg, W. S., and L. R. McLain.

1976. Influence of water temperature on gill sodium, potassium-stimulated ATPase activity in juvenile coho salmon (Oncorhynchus kisutch). Comp. Biochem. Physiol. A 54: 419-421. Article

Zerrenner, A.

2001. Compensatory mechanisms in Lake Champlain sea lamprey (Petromyzon marnius) populations: implications for sea lamprey control. M.S. thesis, 159 p. Univ. Vermont, Burlington, VT.

Zerrenner, A., and J. E. Marsden.

2005. Influence of larval sea lamprey density on transformer life history characteristics in Lewis Creek, Vermont. Trans. Am. Fish. Soc. 134:687-696. Article 